\begin{tabular}{c} 
Global Journal of Mathematical Analysis, $4(1)(2016) 2-5$ \\
Global Journal of Mathematical Analysis \\
SPC \\
Website: $\begin{array}{c}\text { www.sciencepubco.com/index.php/GJMA } \\
\text { doi: } 10.14419 / \text { gima. } 44 i 1.5733 \\
\text { Research paper }\end{array}$ \\
\hline
\end{tabular}

\title{
Common fixed point theorems for weakly compatible non-self mappings in metric spaces of hyperbolic type
}

\author{
Kanayo Stella Eke ${ }^{1}$ \\ ${ }^{1}$ Department of Mathematics, Covenant University, KM. 10, Idiroko Road, P. M. B. 1023, Ota, Ogun State, Nigeria \\ *Corresponding author E-mail:kanayo.eke@covenantuniversity.edu.ng
}

\begin{abstract}
In this paper, we establish common fixed point theorems for a pair of weakly compatible nonself mappings satisfying generalized contractive conditions in metric space of hyperbolic type. The results generalize and extend some results in literature.
\end{abstract}

Keywords: common fixed points, generalized contractive mapping, metric space of hyperbolic type, nonself mappings, weakly compatble mappings.

\section{Introduction}

In literature, fixed point theory has diverse results on fixed point theorems for self-mappings in metric and Banach spaces. However, an area that seems not broadly investigated is the fixed point theorems for non-self mappings. Kirk [1] extended the metric space to metric space of hyperbolic type by replacing Krasnoselskii's result with the framework of convex metric space. The study of fixed point theorems for multivalued non-self mappings in a metric space $(X, d)$ was initiated by Assad [2] and Assad and Kirk [3]. Many authors have studied the existence and uniqueness of fixed and common fixed points result for nonself contraction mappings in cone metric spaces [see; 4, 5, 6, 7 ]. Some authors studied common fixed point theorems for non-self mappings in metric spaces of hyperbolic type [See: 8, 9]. Motivated by Jankovic et al. [7], we prove some common fixed point theorems for a pair of weakly compatible non-self mappings satisfying a generalized contraction condition in the setting of metric space of hyperbolic type.

Throughout our consideration, we suppose that $(X, d)$ is a metric space which contains a family $L$ of metric segments (isometric images of real line segment) such that

a) each two points $x, y \in X$ are endpoints of exactly one number $\operatorname{seg}[\mathrm{x}, \mathrm{y}]$ of $\mathrm{L}$, and

b) If $u, x, y \in X$ and if $z \in \operatorname{seg}[x, y]$ satisfies $d(x, z)=\lambda d(x, y)$ for $\lambda \in[0,1]$ then

$d(u, z) \leq(1-\lambda) d(u, x)+\lambda d(u, y)$

A space of this type is called metric space of hyperbolic type.

The following definition was introduced by Jungck et al. [4] in the setting of cone metric spaces.

Definition 1.1 Let $(X, d)$ be a complete cone metric space, let $\mathrm{C}$ be a non empty closed subset of $X$, and let $f, g: C \rightarrow X$ be non-self mappings. Denote for $x, y \in C$
$M_{1}^{f, g}=\left\{d(g x, g y), d(f x, g x), d(f y, g y), \frac{d(f x, g y)+d(f y, g x)}{2}\right\}$

Then $f$ is called a generalized $g_{M_{1}}$-contractive mapping in $C$ into $X$ if, for some $\lambda \in(0, \sqrt{2}-1)$, there exists $U(x, y) \in M_{1}^{f, g}$ such that for all $x, y \in C$,

$d(f x, f y) \leq \lambda U(x, y)$

\section{Main results}

Jankovic et al. [7] proved the following fixed point theorem for a pair of non-self mappings defined on a nonempty closed subset of complete metrically convex cone metric spaces with new contractive conditions.

Theorem 2.1: Let $(X, d)$ be a complete cone metric space, let $K$ be a non empty closed subset of $X$ such that for each $x \in C$ and $y \notin C$ there exists a point $z \in \delta K$ (the boundary of $K$ ) such that $d(x, z)+d(z, y)=d(x, y)$.

Suppose that $f, g: C \rightarrow X$ are such that $f$ is a generalized $g_{M_{1}}$ contractive mapping of $C$ into $X$ and

(i) $\delta C \subseteq g C, f C \cap C \subseteq g C$,

(ii) $g x \in \delta C \Longrightarrow f x \in C$,

(iii) $g C$ is closed in $X$.

Then the pair $(f, g)$ has a coincidence point. Moreover, if (f, g) are coincidentally commuting, then $f$ and $g$ have a unique common fixed point.

In this paper, we extend the above theorem to fixed point theorem of weakly compatible non- self mappings in metric space of hyperbolic type.

We state and prove our main result as follows. 
Theorem 2.2: Let $X$ be a metric space of hyperbolic type, $K$ a non-empty closed subset of $X$ and $\delta K$ the boundary of $K$. Let $\delta K$ be nonempty and let $T: K \rightarrow X$ and $f: K \cap T(K) \rightarrow X$ be two non-selfmappings satisfying the following conditions:

$d(f x, f y) \leq \lambda . \mu$

where

$\left.\mu \in\left\{d(T x, T y), d(T x, f x), d(T y, f y), \frac{d(T x, f y)+d(T y, f x)}{2}\right\}\right)$

for all $x, y \in C, 0<\lambda<1$. If

(i) $\delta K \subset T K, f K \cap K \subset T K$,

(ii) $T x \in \delta K \Longrightarrow f x \in K$,

(iii) $f K \cap K$ is complete.

Then $f$ and $T$ have a coincidence point $\mathrm{z}$ in X. Moreover, if $f$ and $T$ are weakly compatible, then $z$ is the unique common fixed point of $f$ and $T$.

Proof: Let $x \in \delta K$ be arbitrary. We construct three sequences, $\left\{x_{n}\right\}$ and $\left\{z_{n}\right\}$ in $K$ and a sequence $\left\{y_{n}\right\}$ in $f K \subset X$ as follows. Choose $z_{0}=x$. Since $z_{0} \in \delta K$ then there exists $x_{0} \in K$ such that $z_{0}=T x_{0} \in \delta K$. By (iii) $f x_{0} \in K$. Now choose $y_{1}=f x_{0}$ with $y_{1} \in f K \subset X$. This implies that $f x_{0} \in f K \cap K \subset T K$. Set $y_{1}=f x_{0}$, we choose $x_{1} \in K$ such that $T x_{1}=f x_{0}$. Hence $z_{1}=T x_{1}=f x_{0}=y_{1}$. This gives $y_{2}=f x_{1}$.

Since $y_{2} \in f K \cap K$ then $y_{2} \in T K$ by (ii). Let $x_{1} \in K$ with $z_{1}=T x_{1} \in \delta K$ such that $z_{2}=T x_{2}=f x_{1}=y_{2}$. If $f x_{1}=y_{2} \notin K$, then there exists $z_{2} \in \delta K\left(z_{2} \notin y_{2}\right)$ such that $z_{2} \in \operatorname{seg}\left[y_{1}, y_{2}\right]$. Since $x_{2} \in K$, then by (i) we have $T x_{2}=z_{2}$. Hence

$z_{2} \in \delta K \cap \operatorname{seg}\left[y_{1}, y_{2}\right]$.

We can choose $y_{3} \in f K \cap K$, and by (ii), $y_{3} \in T K$ and let $x_{2} \in K$ such that $T x_{3}=y_{3}=f x_{2}$. Continuing in the process, we construct three sequence $\left\{x_{n}\right\} \subseteq K,\left\{z_{n}\right\} \subseteq K$ and $\left\{y_{n}\right\} \subseteq f K \subset X$ such that

(a) $y_{n}=f x_{n-1}$

(b) $z_{n}=T x_{n}$,

(c) $z_{n}=y_{n}$ if and only if $y_{n} \in K$

(d) $z_{n} \notin y_{n}$ whenever $y_{n} \notin K$ and $z_{n} \in \delta K$ such that

$z_{n} \in \delta K \cap \operatorname{seg}\left[f x_{n-2}, f x_{n-1}\right]$.

This proves that $\mathrm{f}$ and $\mathrm{T}$ are non-self mappings.

Remark 2.3: By (d) if $z_{n} \neq y_{n}$, then $z_{n} \in \delta K$ and combining (b), (ii) and (a) we have $z_{n+1}=y_{n+1}$. Likewise $z_{n-1}=y_{n-1} \in K$. If $z_{n-1} \in \delta K$, then it implies $z_{n}=y_{n} \in K$.

Next, we show that $x_{n} \neq x_{n+1}$ for all n. From (a), (b), (c) and (d) we can establish three possibilities.

(1) $z_{n}=y_{n} \in K$ and $z_{n+1}=y_{n+1}$;

(2) $z_{n}=y_{n} \in K$ but $z_{n+1} \neq y_{n+1}$;

(3) $z_{n} \neq y_{n} \in K$ in which case $z_{n} \in \delta K \cap \operatorname{seg}\left[f x_{n-2}, f x_{n-1}\right]$.

Now

Case (1)

Let $z_{n}=y_{n} \in K$ and $z_{n+1}=y_{n+1}$. Using (2.1) we obtain

$d\left(z_{n}, z_{n+1}\right)=d\left(y_{n}, y_{n+1}\right)=d\left(f x_{n-1}, f x_{n}\right) \leq \lambda \cdot \mu_{n}$

where $\mu_{n} \in\left\{d\left(T x_{n-1}, T x_{n}\right), d\left(T x_{n-1}, f x_{n-1}\right), d\left(T x_{n}, f x_{n}\right)\right.$,

$$
\begin{aligned}
& \left.\left.\frac{d\left(T x_{n-1}, f x_{n}\right)+d\left(T x_{n}, f x_{n-1}\right)}{2}\right\}\right) \\
& =\left\{d\left(z_{n-1}, z_{n}\right), d\left(z_{n-1}, y_{n}\right), d\left(z_{n}, y_{n+1}\right), \frac{d\left(z_{n-1}, y_{n+1}\right)+d\left(z_{n}, y_{n}\right)}{2}\right\} \\
& =\left\{d\left(z_{n-1}, z_{n}\right), d\left(z_{n-1}, z_{n}\right), d\left(z_{n}, z_{n+1}\right), \frac{d\left(z_{n-1}, z_{n+1}\right)+0}{2}\right\} \\
& =\left\{d\left(z_{n-1}, z_{n}\right), d\left(z_{n-1}, z_{n}\right), d\left(z_{n}, z_{n+1}\right), \frac{d\left(z_{n-1}, z_{n}\right)+d\left(z_{n}, z_{n+1}\right)}{2}\right\}
\end{aligned}
$$

Obviously, there are infinite many $n$ such that at least one of the following cases holds:

I: $d\left(z_{n}, z_{n+1}\right) \leq \lambda d\left(z_{n-1}, z_{n}\right)$

II: $d\left(z_{n}, z_{n+1}\right) \leq \lambda \cdot d\left(z_{n-1}, z_{n}\right)$
III: $d\left(z_{n}, z_{n+1}\right) \leq \lambda \cdot d\left(z_{n}, z_{n+1}\right)$. A contradiction.

$\left.\mathrm{IV}: d\left(z_{n}, z_{n+1}\right) \leq \lambda \cdot \frac{d\left(z_{n-1}, z_{n}\right)+d\left(z_{n}, z_{n+1}\right)}{2}\right\}$

$\leq \frac{\lambda}{2}\left(d\left(z_{n-1}, z_{n}\right)+\frac{\lambda}{2} d\left(z_{n}, z_{n+1}\right)\right)$ implies

$d\left(z_{n}, z_{n+1}\right) \leq \lambda d\left(z_{n-1}, z_{n}\right)$

From I, II, III, IV it follows that

$d\left(z_{n}, z_{n+1}\right) \leq \lambda \cdot d\left(z_{n-1}, z_{n}\right)$

Case 2

Let $z_{n}=y_{n} \in K$ but $z_{n+1} \neq y_{n+1}$. Then $z_{n+1} \in \delta K \cap \operatorname{seg}\left[y_{n}, y_{n+1}\right]$. From (1.1) with $u=y$, we obtain

$d(y, z) \leq(1-\lambda) d(x, y)$

Therefore

$d(x, y) \leq d(x, z)+d(z, y) \leq \lambda d(x, y)+(1-\lambda) d(x, y)=d(x, y)$

Hence

$z \in \operatorname{seg}[x, y] \Longrightarrow d(x, z)+d(z, y)=d(x, y)$.

Since $z_{n+1} \in \operatorname{seg}\left[y_{n}, y_{n+1}\right]=\operatorname{seg}\left[z_{n}, y_{n+1}\right]$, we have

$d\left(z_{n}, z_{n+1}\right)=d\left(y_{n}, z_{n+1}\right)=d\left(y_{n}, y_{n+1}\right)-d\left(z_{n+1}, y_{n+1}\right)<$ $d\left(y_{n}, y_{n+1}\right)$

In view of case (1), we obtain

$d\left(y_{n}, y_{n+1}\right) \leq \lambda \cdot d\left(z_{n-1}, z_{n}\right)$.

This implies that $d\left(z_{n}, z_{n+1}\right) \leq \lambda \cdot d\left(z_{n-1}, z_{n}\right)$.

Case (3)

$z_{n} \neq y_{n} . \quad$ Then $z_{n} \in \delta K \cap \operatorname{seg}\left[f x_{n-2}, f x_{n-1}\right] . \quad$ i.e. $\quad z_{n} \in$ $\delta K \cap \operatorname{seg}\left[y_{n-1}, y_{n}\right]$

By remark (2.3) we have $z_{n+1}=y_{n+1}$ and $z_{n-1}=y_{n-1}$. This implies that

$$
\begin{aligned}
d\left(z_{n}, z_{n+1}\right) & =d\left(z_{n}, y_{n+1}\right) \\
\leq & d\left(z_{n}, y_{n}\right)+d\left(y_{n}, y_{n+1}\right) \\
= & d\left(z_{n-1}, y_{n}\right)-d\left(z_{n}, z_{n-1}\right)+d\left(y_{n}, y_{n+1}\right) \\
= & d\left(y_{n-1}, y_{n}\right)-d\left(z_{n}, z_{n-1}\right)+d\left(y_{n}, y_{n+1}\right)
\end{aligned}
$$

We shall find $d\left(y_{n-1}, y_{n}\right)$ and $d\left(y_{n}, y_{n+1}\right)$. Since $z_{n-1}=y_{n-1}$ then we can conclude that

$d\left(y_{n-1}, y_{n}\right) \leq \lambda . d\left(z_{n-2}, z_{n-1}\right)$,

with respect to case (2).

Now

$d\left(y_{n}, y_{n+1}\right)=d\left(f x_{n-1}, f x_{n}\right) \leq \lambda \cdot \mu_{n}$

where $\mu_{n} \in\left\{d\left(T x_{n-1}, T x_{n}\right), d\left(T x_{n-1}, f x_{n-1}\right), d\left(T x_{n}, f x_{n}\right)\right.$,

$$
\begin{aligned}
& \left.\left.\quad \frac{d\left(T x_{n-1}, f x_{n}\right)+d\left(T x_{n}, f x_{n-1}\right)}{2}\right\}\right) \\
& =\left\{d\left(z_{n-1}, z_{n}\right), d\left(z_{n-1}, y_{n}\right), d\left(z_{n}, y_{n+1}\right), \frac{d\left(z_{n-1}, y_{n+1}\right)+d\left(z_{n}, y_{n}\right)}{2}\right\} \\
& =\left\{d\left(z_{n-1}, z_{n}\right), d\left(z_{n-1}, y_{n}\right), d\left(z_{n}, z_{n+1}\right), \frac{d\left(z_{n-1}, z_{n+1}\right)+d\left(z_{n}, y_{n}\right)}{2}\right\} \\
& \leq\left\{d\left(z_{n-1}, z_{n}\right), d\left(z_{n-1}, y_{n}\right), d\left(z_{n}, z_{n+1}\right),\right. \\
& \left.\frac{d\left(z_{n-1}, z_{n}\right)+d\left(z_{n}, z_{n+1}\right)+d\left(z_{n}, z_{n-1}\right)-d\left(z_{n-1}, y_{n}\right)}{2}\right\} \\
& \leq\left\{d\left(z_{n-1}, z_{n}\right), d\left(y_{n-1}, y_{n}\right), d\left(z_{n}, z_{n+1}\right), \frac{2 d\left(z_{n-1}, z_{n}\right)+d\left(z_{n}, z_{n+1}\right)}{2}\right\}
\end{aligned}
$$

Clearly, there are infinite many $n$ such that at least one of the following cases holds: 


$$
\begin{aligned}
& \text { I: } d\left(y_{n}, y_{n+1}\right) \leq \lambda \cdot d\left(z_{n-1}, z_{n}\right) \\
& \text { II: } d\left(y_{n}, y_{n+1}\right) \leq \lambda d\left(y_{n-1}, y_{n}\right) \leq \lambda^{2} \cdot d\left(z_{n-2}, z_{n-1}\right) \\
& \text { III: } d\left(y_{n}, y_{n+1}\right) \leq \lambda \cdot d\left(z_{n}, z_{n+1}\right) \\
& \text { IV: } d\left(y_{n}, y_{n+1}\right) \leq \lambda \cdot d\left(z_{n}, z_{n-1}\right)+\frac{\lambda}{2} d\left(z_{n}, z_{n+1}\right) \\
& \text { Substituting I, II, III, IV in }(2.4) \text { yields } \\
& d\left(z_{n}, z_{n+1}\right) \leq \lambda \cdot d\left(z_{n-2}, z_{n-1}\right)-d\left(z_{n}, z_{n-1}\right)+\lambda \cdot \mu_{n}
\end{aligned}
$$

from which we have four cases:

$$
\begin{aligned}
\mathrm{V}: d\left(z_{n}, z_{n+1}\right) & \leq \lambda \cdot d\left(z_{n-2}, z_{n-1}\right)-d\left(z_{n}, z_{n-1}\right)+\lambda \cdot d\left(z_{n-1}, z_{n}\right) \\
\leq & \lambda \cdot d\left(z_{n-2}, z_{n-1}\right)-(1-\lambda) d\left(z_{n}, z_{n-1}\right) \\
\leq & \lambda \cdot d\left(z_{n-2}, z_{n-1}\right)
\end{aligned}
$$

VI: $d\left(z_{n}, z_{n+1}\right) \leq \lambda \cdot d\left(z_{n-2}, z_{n-1}\right)-d\left(z_{n}, z_{n-1}\right)+\lambda^{2} \cdot d\left(z_{n-2}, z_{n-1}\right)$

$$
\begin{aligned}
& \leq\left(\lambda+\lambda^{2}\right) d\left(z_{n-2}, z_{n-1}\right)-d\left(z_{n}, z_{n-1}\right) \\
& \leq\left(\lambda+\lambda^{2}\right) d\left(z_{n-2}, z_{n-1}\right)
\end{aligned}
$$

VII: $d\left(z_{n}, z_{n+1}\right) \leq \lambda \cdot d\left(z_{n-2}, z_{n-1}\right)-d\left(z_{n}, z_{n-1}\right)+\lambda \cdot d\left(z_{n}, z_{n+1}\right)$

$$
\begin{aligned}
& \leq \frac{\lambda}{1-\lambda} d\left(z_{n-2}, z_{n-1}\right)-\frac{1}{1-\lambda} d\left(z_{n}, z_{n-1}\right) \\
& \leq \frac{\lambda}{1-\lambda} d\left(z_{n-2}, z_{n-1}\right)
\end{aligned}
$$

VIII: $d\left(z_{n}, z_{n+1}\right) \leq \lambda \cdot d\left(z_{n-2}, z_{n-1}\right)-d\left(z_{n}, z_{n-1}\right)+\lambda \cdot d\left(z_{n}, z_{n-1}\right)+$ $\frac{\lambda}{2} d\left(z_{n}, z_{n+1}\right)$

$$
\begin{aligned}
& \leq \lambda \cdot d\left(z_{n-2}, z_{n-1}\right)-(1-\lambda) d\left(z_{n}, z_{n-1}\right)+\frac{\lambda}{2} d\left(z_{n}, z_{n+1}\right) \\
& \leq \frac{2 \lambda}{2-\lambda} \cdot d\left(z_{n-2}, z_{n-1}\right)-\frac{2(1-\lambda)}{2-\lambda} d\left(z_{n}, z_{n-1}\right) \\
& \leq \frac{2 \lambda}{2-\lambda} \cdot d\left(z_{n-2}, z_{n-1}\right)
\end{aligned}
$$

From V, VI, VII, VIII we obtain

$d\left(z_{n}, z_{n+1}\right) \leq k \cdot d\left(z_{n-2}, z_{n-1}\right)$ where

$k=\max \left\{\lambda, \lambda+\lambda^{2}, \frac{\lambda}{1-\lambda}, \frac{2 \lambda}{2-\lambda}\right\}$

Combining Cases 1, 2, 3 we get

$d\left(z_{n}, z_{n+1}\right) \leq k . \omega_{n}$

where $\omega_{n} \in\left\{d\left(z_{n-2}, z_{n-1}\right), d\left(z_{n-1}, z_{n}\right)\right\}$ and

$k=\max \left\{\lambda, \lambda+\lambda^{2}, \frac{\lambda}{1-\lambda}, \frac{2 \lambda}{2-\lambda}\right\}$

Following the procedure of Assad and Kirk [3], it can be easily verify by induction that for $n>1$

$d\left(z_{n}, z_{n+1}\right) \leq k^{\frac{n-1}{2}} . \omega_{2}$

where $\omega_{2} \in\left\{d\left(z_{0}, z_{1}\right), d\left(z_{1}, z_{2}\right)\right\}$.

For $n>m$ and using (2.5) and the triangle inequality we have

$$
\begin{aligned}
d\left(z_{n}, z_{m}\right) & \leq d\left(z_{n}, z_{n-1}\right)+d\left(z_{n-1}, z_{n-2}\right)+\cdots+d\left(z_{m+1}, z_{m}\right) \\
& \leq\left(k^{\frac{n-1}{2}}+k^{\frac{n-2}{2}}+\cdots+k^{\frac{m-1}{2}}\right) \cdot \omega_{2} \\
& \leq \frac{\sqrt{k}^{m-1}}{1-\sqrt{k}} \cdot \omega_{2} \rightarrow 0, \quad \text { as } m \rightarrow \infty .
\end{aligned}
$$

The sequence is Cauchy. Since $z_{n}=f x_{n-1} \in f K \cap K$ is complete, there is some $z \in f K \cap K$ such that $z_{n} \rightarrow z$. Let $w$ in $\mathrm{K}$ be such that $T w=z$. By the construction of $\left\{z_{n}\right\}$, there is a subsequence $\left\{z_{n_{k}}\right\}$ such that $z_{n_{k}}=y_{n_{k}}=f x_{n_{k-1}}$ and $f x_{n_{k-1}} \rightarrow z$ We show that $f w=z$.

$d(f w, z) \leq d\left(f w, f x_{n_{k-1}}\right)+d\left(f x_{n_{k-1}}, z\right) \leq \lambda \cdot \mu_{n_{k}}+d\left(f x_{n_{k-1}}, z\right)$

where

$\mu_{n_{k}} \in\left\{\left(d\left(T w, T x_{n_{k-1}}\right), d\left(T x_{n_{k-1}}, f x_{n_{k-1}}\right), d(T w, f w)\right.\right.$,

$$
\left.\frac{d\left(T w, f x_{n_{k-1}}\right)+d\left(T x_{n_{k-1}}, f w\right)}{2}\right\}
$$

Taking $z_{n_{k}}=y_{n_{k}}=f x_{n_{k-1}} \rightarrow z$ as $n \rightarrow \infty$ yields $\mu_{n} \in\left\{0, d(z, f w), 0, \frac{d(z, f w)}{2}\right\}$

$\mu_{n} \in\left\{d(z, f w), \frac{d(z, f w)}{2}\right\}$

Thus, we have

i) $d(f w, z) \leq \lambda d(z, f w)+d\left(f x_{n_{k-1}}, z\right) \leq \lambda d(z, f w)$

Since $\lambda<1$ then $d(f w, z)=0$. This implies $z=f w$

ii) $d(f w, z) \leq \frac{\lambda}{2} d(f w, z)$

Since $\lambda<1$ then $d(f w, z)=0$. Hence $z=f w$. In all cases we have $z=f w$.

Suppose that $\mathrm{T}$ and $\mathrm{f}$ are weakly compatible, then we have $z=f w=T w \Longrightarrow f z=f T w=T f w=T z$.

Next we prove that $z=f z=T z$. Suppose $z \neq f z$ then using 2.1 we obtain

$d(f z, z)=d(f z, f w) \leq \lambda . \mu$

where

$\mu \in\{d(T z, T w), d(T z, f z), d(T w, f w)$,

$\left.\frac{d(T z, f w)+d(T w, f z)}{2}\right\}$

$$
\begin{aligned}
& \leq\left\{d(z, z), d(z, f z), d(z, z), \frac{d(z, z)+d(z, f z)}{}\right\} \\
& \leq\left\{d(z, f z), \frac{d(z, f z)}{2}\right\}
\end{aligned}
$$

Case (i)

$d(f z, z) \leq \lambda d(f z, z)$ It is a contradiction. Hence $z=f z$

Case(ii)

$d(f z, z) \leq \frac{\lambda}{2} d(f z, z)$

It is also a contradiction. This imples that $z=f z$. Therefore we obtain $z=f z=T z$. Thus $T$ and $f$ have a common fixed point. The uniqueness of the common fixed point follows easily from $(2,1)$.

Remark 2.4 : Theorem 2.2 is an extension of the result of jankovic [7] .

Setting $T=I_{x}$, the identity mapping of $X$ in Theorem 2.2 , we obtain the following result.

Corollary 2.5: Let $(X, d)$ be metric space of hyperbolic type, $K$ a non-empty closed subset of $X$ and $\delta K$ the boundary of $K$. Let $\delta K$ be nonempty such that $f: K \rightarrow K$ satisfies the condition $d(f x, f y) \leq \lambda . \mu$ where

$\left.\mu \in\left\{d(x, y), d(x, f x), d(y, f y), \frac{d(x, f y)+d(y, f x)}{2}\right\}\right)$

for all $x, y \in k, 0<\lambda<1$ and $f$ has the additional property that for each $x \in \delta K$ and $f x \in K$. Then $f$ has a unique fixed point.

Corollary 2.6: Let $X$ be a metric space of hyperbolic type, $K$ a non-empty closed subset of $X$ and $\delta K$ the boundary of $K$. Let $\delta K$ be nonempty and let $T: K \rightarrow X$ and $f: K \cap T(K) \rightarrow X$ be two non-self- mappings satisfying the following conditions:

$d(f x, f y) \leq \lambda(d(T x, f x)+d(T y, f y))$

for all $x, y \in C, 0<\lambda<\frac{1}{2}$. If 
(i) $\delta K \subset T K, f K \cap K \subset T K$,

(ii) $T x \in \delta K \Longrightarrow f x \in K$,

(iii) $f K \cap K$ is complete.

Then $f$ and $T$ have a coincidence point $\mathrm{z}$ in X. Moreover, if $f$ and $T$ are weakly compatible, then $z$ is the unique common fixed point of $f$ and $T$.

Example 2.7 : Let $X$ be the set of real numbers with the usual metric, $K=[0,+\infty)$ and let $T: K \rightarrow X$ and $f: K \cap T(K) \rightarrow X$ be two non-self mappings defined by $T x=4 x$ and $f x=\frac{4 x}{1+4 x}$ for all $x \in K$.

Taking $x=\frac{1}{2}$ and $y=\frac{1}{4}$ we obtain $\lambda=\frac{1}{6}$. Thus $T$ and $f$ satisfied (2. 1) and all the hypotheses in Theorem 2.2 are satisfied. $T$ and $f$ have a unique common fixed point $z=0$.

\section{Conclusion}

In this section, we proved that in a metric space of hyperbolic type, two non-self mappings $f$ and $T$ satisfying certain contractive conditions have a coincidence point. Moreover, if the maps are weakly compatible then $f$ and $T$ have a unique common fixed point. We gave an example to validate our results.

\section{References}

[1] W. A. Kirk, Krasnoselskii's iteration process in hyperbolic space, Numer. Funct. Anal. and Optimiz., 4(1982), 371-381.

[2] N. A. Assad, On a fixed point theorem in Banach space, Tamkang J. Math., 7(1976), 91-94.

[3] N. A. Assad and W. A. Kirk, Fixed point theorems for set-valued mappings of contractive type, Pacific J. Math. 43(1972), 553-562.

[4] G. Jungck, S. Radenovic, V. Radejovic, V. Rakocevic, Common fixed point theorems for weakly compatible pairs on cone metric spaces, Fixed Point Theory Appl. 2009, Article ID 643840(2009), doi: 10.1155/2009/643840.

[5] R. Sumitra, V. R. Uthariaraj, R. Hemavathy, P . Vijayaraju, Common fixed point theorem for non-self mappings satisfying generalized Ciric type contraction condition in cone metric space, Fixed Point Theory and Applications, (2010), Article ID 408086, 17 pages.

[6] S. Radenovic and B. E. Rhoades, Fixed point theorem for two non-self mappings in cone metric spaces, Computers and Mathematics with Applications, 57(2009), 1701-1707.

[7] S. Jankovic, Z. Kadelburg, S. Radenovic, BE Rhoades, Assad-Kirk type fixed point theorems for a pair of non -self mappings on cone metric spaces, Fixed Point Theory Appl. 2009, Article ID 761086(2009),

[8] L. B. Ciric, Contractive-type non-self mappings on metric spaces of hyperbolic type, J. Math. Anal. Appl., 317(2006), 28-42.

[9] L. Ciric, V. Rakocevic, S. Radenovic, M. Rajovic, R. Lazovic, Common fixed point theorems for non-self mappings in metric spaces of hyperbolic type, Journal of Computational and Applied Mathematics, 233(2010), 2966-2974.

[10] W. Takahashi, A convexity in metric spaces and nonexpansive mappings, I, Kodai Math. Sem. Rep. 22(1970), 142-149. 